\title{
Diagnóstico e reabilitação agroambiental de trecho de bacia hidrográfica por sensoriamento remoto e turbidez da água
}

\author{
Oswaldo Julio Vischi Filho(1), Liatar Giorge Corsato(1), Jorge Aparecido Quiessi(1), Oscar Yoshikatsu Kanno(1), \\ Raul Barros Penteado(1), Roberto Mikio Arabori( ${ }^{(1)}$, Lucia Cristina Camargo Belorte ${ }^{(1)}$ e Márcio Emanoel de Lima ${ }^{(1)}$ \\ (1)Secretaria de Agricultura e Abastecimento do Estado de São Paulo, Coordenadoria de Defesa Agropecuária, Avenida Brasil, no 2.340, CEP \\ 13070-178 Campinas, SP, Brasil. E-mail: ovischi@gmail.com, liatar@cda.sp.gov.br, jorge.quiessi@cda.sp.gov.br, oscar.kanno@cda.sp.gov.br, \\ raul.barros@cda.sp.gov.br, roberto.arabori@cda.sp.gov.br, cclucia@gmail.com,marcioemanoel@bol.com.br
}

Resumo - O objetivo deste trabalho foi identificar erosões em bacia hidrográfica e avaliar práticas conservacionistas de manejo do solo para a recuperação da degradação, por meio do monitoramento de indicadores de qualidade de água e por imagens de satélites. O monitoramento, por um período de 14 anos, foi realizado em 14.076 ha da bacia do Rio do Peixe, selecionada por ser a mais degradada do Estado de São Paulo, que abrangem 176 propriedades agrícolas exploradas basicamente com pastagens e café. Destas, 82 apresentaram algum tipo de erosão, além de 12 trechos de estradas municipais que contribuíram com processos erosivos nas áreas agrícolas. As práticas de manejo conservacionista do solo e da água implantadas em 86 propriedades da bacia permitem alteração positiva da paisagem e de rendimento da atividade agrícola, mudança comprovada pelas imagens aéreas e pelos indicadores de qualidade da água. A metodologia apresentada de monitoramento e de reabilitação agroambiental é viável e pode contribuir para o manejo e o monitoramento de microbacias.

Termos para indexação: assoreamento, bacia hidrográfica, cobertura vegetal, conservação do solo, erosão hídrica, imagem aérea.

\section{Agri-environmental diagnostic and rehabilitation in a stretch of a hydrographic basin assessed by remote sensing and water turbidity}

\begin{abstract}
The objective of this work was to diagnose erosions in a hydrographic basin and to evaluate conservationist soil management practices for degradation recovery, by monitoring water quality indicators and satellite images. Monitoring was done for 14 years in 14,076 ha of the basin of Rio do Peixe, which was selected for being the most degraded one in the state of São Paulo, Brazil, circumscribing 176 farms, basically explored with pastures and coffee. Out of these farms, 82 showed some kind of erosion, besides 12 stretches of municipal roads that contributed to the erosion processes in the agricultural areas. The conservationist soil and water management practices established in 86 of the farms at the basin allow positive changes on the landscape and on the income from agricultural activity, which were shown in the aerial photos and by the water quality indicators. The adopted monitoring and agri-environmental rehabilitation methodologies are viable and may contribute to managing and monitoring microbasins.
\end{abstract}

Index terms: riverbed silting, hydrographic basin, vegetation cover, soil conservation, hydraulic erosion, aerial photo.

\section{Introdução}

A inexistência ou simplesmente a adoção errônea de práticas de conservação do solo em áreas de cultivo, nas propriedades agrícolas, contribuem para o assoreamento e degradação dos recursos hídricos e podem transformar um rio caudaloso em um córrego espraiado, fato comumente verificado no Brasil e em outros países.

O ciclo degradador - provocado por desmatamentos, exposição do solo às intempéries, intensa utilização de insumos e escoamento superficial - gera impactos negativos decorrentes da erosão, o que é agravado por seu difícil e oneroso controle. Para minimizar tais efeitos, é necessário que se estabeleça um sistema de conservação do solo associado ao monitoramento do uso do solo e da água na paisagem agrícola (Santos et al., 2007).

Estudos que avaliam a degradação do solo em diversas bacias hidrográficas brasileiras resumemse, na maioria dos casos, a diagnósticos. No entanto, o governo federal instituiu, por meio do Decreto n. $^{\circ}$ 94.076 de 05 de março de 1987 (Brasil, 1987), o Programa Nacional de Microbacias Hidrográficas 
e agências governamentais, que tem implementado programas voltados para a conservação do solo e da água, por meio do fomento ao cultivo mínimo e ao uso de plantas de cobertura como, por exemplo, o Programa Estadual de Microbacias Hidrográficas do Estado de São Paulo (PEMB) e o Programa Produtor de Água da Agência Nacional de Águas (ANA, 2009).

Um dos desafios do Programa Nacional de Microbacias consiste em avaliar e monitorar a eficiência das práticas recomendadas em reduzir as taxas de erosão, considerando-se a escala de uma bacia hidrográfica, avaliadas por meio da variabilidade da produção de sedimentos que, por sua vez, é determinada pela integração dos fluxos de sedimentos em suspensão dentro de um certo intervalo de tempo (Minella et al., 2007).

A fiscalização do uso e conservação do solo agrícola no Estado de São Paulo é uma atividade disciplinada pela Lei 6.171/88 (São Paulo, 1988), de competência exclusiva da Secretaria de Agricultura e Abastecimento do Estado de São Paulo, por meio da Coordenadoria de Defesa Agropecuária (CDA). Esse trabalho prevê a restauração das áreas degradadas da bacia, com adequação das propriedades às práticas conservacionistas sustentáveis.

Vital et al. (1999), em uma microbacia no Vale do Paraíba, inferiram que, ao longo de sete anos de crescimento de uma plantação de eucalipto, o deflúvio anual da microbacia diminuiu gradativamente e, após a realização do corte raso, houve aumento de $48 \%$ das perdas de sedimentos em suspensão e, além disso, aumento dos valores da turbidez, cor, condutividade e concentração de sedimentos na água do deflúvio. Donadio et al. (2005) verificaram a influência de remanescentes da vegetação ciliar e da ação antrópica sobre a qualidade da água, na microbacia do Córrego Rico. Os autores concluíram que a presença de remanescentes de vegetação ciliar auxiliou na proteção dos recursos hídricos, e que outros fatores, como períodos de amostragem e características do solo e de seus diferentes usos, influenciaram a qualidade da água dessa microbacia. Outros estudos, como o de Santos et al. (2011), que monitoraram a Microbacia Córrego do Ipê, fazem um relato sobre o uso e a ocupação do solo, e sobre a influência do cultivo de cana-de-açúcar sobre a qualidade de água para fins de irrigação. Esses estudos permitem subsidiar o planejamento hidroagrícola e ambiental da microbacia.
O objetivo deste trabalho foi identificar erosões em bacia hidrográfica e avaliar práticas conservacionistas de manejo do solo para a recuperação da degradação, por meio do monitoramento de indicadores de qualidade de água e por imagens de satélites.

\section{Material e Métodos}

$\mathrm{O}$ trecho estudado da bacia hidrográfica $(\mathrm{BH})$ do Rio do Peixe localiza-se no Município de Vera Cruz, SP, Brasil, e tem seu início a $22^{\circ} 12^{\prime} 57^{\prime \prime} \mathrm{S}$ e $49^{\circ} 44^{\prime} 56^{\prime \prime} \mathrm{W}$, seu final a $22^{\circ} 19^{\prime} 02^{\prime \prime} \mathrm{S}$ e $49^{\circ} 53^{\prime} 53^{\prime \prime} \mathrm{W}$ (Datum WGS84) e faz parte de um trabalho maior, que está sendo realizado em três trechos da mesma $\mathrm{BH}$, localizados em Vera Cruz, Ocauçu e Marília. Os trechos fazem parte da BH que tem 1,08 milhões de hectares (Figura 1), com a nascente no Município de Garça e a foz no Rio Paraná, na divisa entre os municípios de Caiuá, Panorama e Presidente Epitácio.

Nesse trecho da $\mathrm{BH}$, predomina o Argissolo Vermelho-Amarelo abrupto, e a formação geológica compreende um substrato formado por rochas do Grupo Bauru, recobertas localmente por sedimentos neocenozoicos que incluem terraços aluviais pleitocênicos, aluviões atuais, colúvios e regolitos arenosos espessos (Bezerra et al., 2009). O relevo preponderante é o suave-ondulado, no Planalto OcidentalPaulistae, naregião da depressão, éfortemente ondulado nas escarpas (formação denominada Itambé), que separam o planalto da depressão. De acordo com a classificação de Köppen-Geiger, o clima da região é o subtropical úmido, do tipo Cwa, com temperaturas no mês mais quente superiores a $29,7^{\circ} \mathrm{C}$ e, no mês mais frio, inferiores a $10,6^{\circ} \mathrm{C}$, com precipitação pluvial média anual de $1.193 \mathrm{~mm}$, com chuvas mais concentradas no período de novembro a março. Utilizaram-se os dados de precipitações de uma série histórica de 32 anos (média de 1972 a 2004), da região onde o trabalho foi realizado (Figura 2).

$\mathrm{O}$ polígono do trecho da $\mathrm{BH}$ foi demarcado em carta topográfica vetorizada, em que o divisor de águas da $\mathrm{BH}$ foi traçado; o recorte da carta com essas informações foi associado ao programa Google Earth, em que as coordenadas - em graus, minutos e segundos -, no Datum WGS 84, foram espacializadas, tendo-se gerado o contorno da BH (Figura 1).

Os mapas gerados foram utilizados para subsidiar as equipes de trabalho com os parâmetros para a localização das coordenadas e, também, para a marcação 
das propriedades visitadas e os danos encontrados. Todas as propriedades componentes desse trecho da $\mathrm{BH}$ foram visitadas e diagnosticadas conforme metodologia da Coordenadoria de Defesa Agropecuária (CDA) (São Paulo, 2015). Para cada propriedade, aplicou-se uma checklist, com anotações sobre o uso e a ocupação do solo, culturas predominantes e erosões - classificadas, fotografadas e georreferenciadas. Quando se detectavam erosões, a partir do relatório gerado por ocasião da visita que apontava tal fato, o proprietário contratava um engenheiro-agrônomo que elaborava projeto técnico de conservação do solo e água, com indicação sobre a solução para sanar os danos, recuperar o solo e readequar a propriedade. Os projetos técnicos foram implantados conforme cronograma de obras, para solucionar as pendências levantadas. A equipe da CDA visitou cada propriedade de 2 a 5 vezes, durante a implantação do projeto, ou na data do diagnóstico (primeira inspeção), ou para acompanhar a execução do projeto técnico ou, ainda, na liberação da propriedade após a finalização das obras.

Os dados coletados durante o diagnóstico foram inseridos em um banco de dados próprio e trabalhados no programa Autodesk MAP 5, em um layer com a carta vetorizada do IBGE, na escala 1:50.000. Os pontos com as coordenadas de localização das propriedades e das erosões foram plotados sobre a carta vetorizada e também no Google Earth, e as imagens geradas foram estudadas e salvas em arquivo "kml" (extensão de arquivo de leitura do programa Google Earth). Para avaliar o sucesso desse tipo de atividade, quanto ao aumento da quantidade de água armazenada na $\mathrm{BH}$, utilizam-se: pluviógrafos, distribuídos na $\mathrm{BH}$, para se

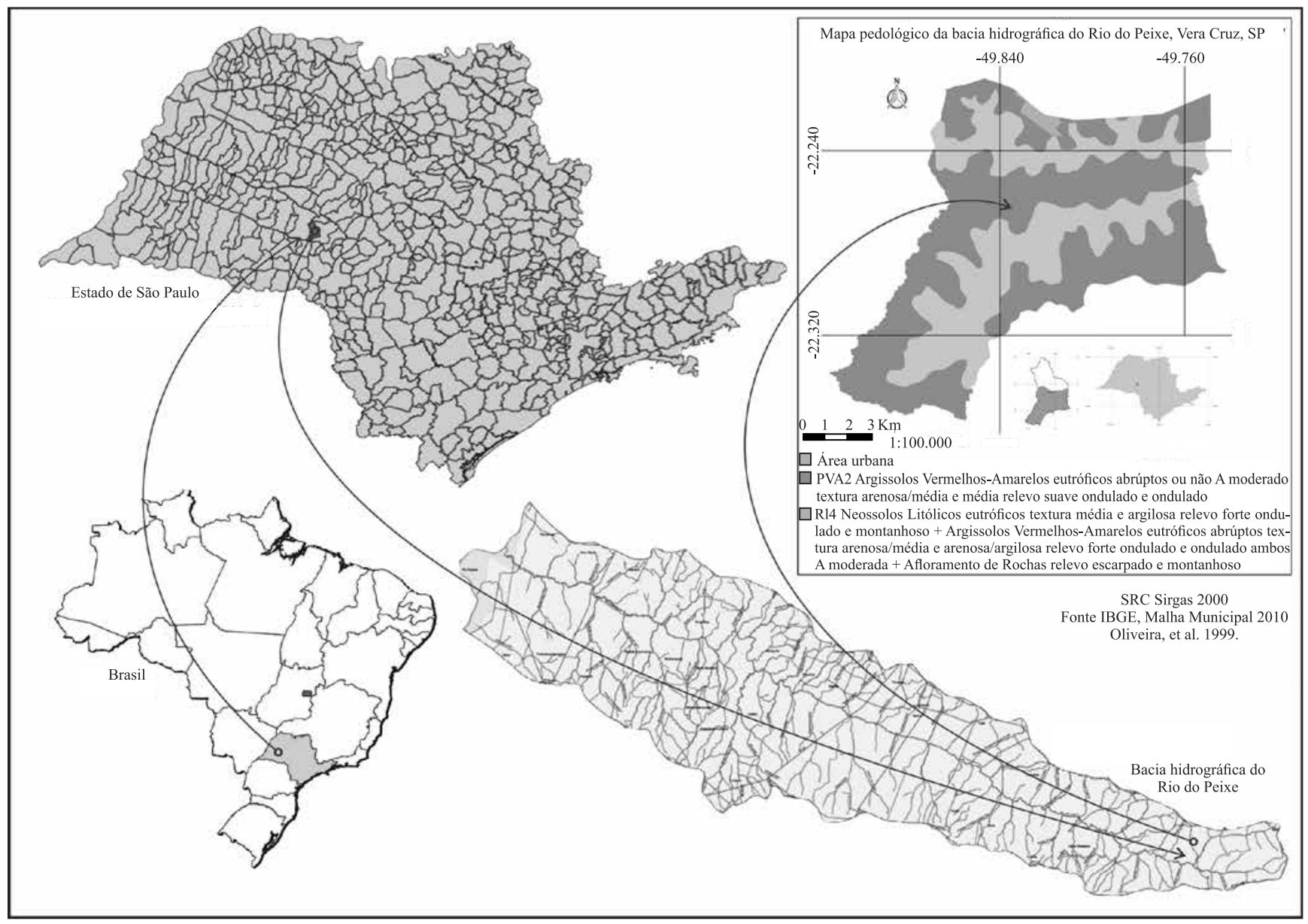

Figura 1. Localização da Bacia Hidrográfica do Rio do Peixe, tendo-se como referências: A, Brasil; B, Estado de São Paulo, com o Município de Vera Cruz evidenciado; C, Bacia Hidrográfica do Rio do Peixe; e D, mapa de solos do trecho da Bacia Hidrográfica do Rio do Peixe (escala gráfica). 
obterem os índices pluviométricos (São Paulo, 2014b; Figura 2); e a medição de vazão do curso d'água, por meio de uma seção de vertedouro conhecida, onde se instalou uma régua linimétrica para medição da curva-chave de vazão ou cota-vazão e, a partir das leituras diárias da régua, se obteve o histórico de vazão.

Quando há aumento de vazão na época de estiagem, nos meses de maio, junho, julho e agosto, é sinal de que as práticas conservacionistas tiveram sucesso e se armazenou mais água no solo da BH. No caso do Rio do Peixe, há uma série histórica de fluviometria de 1967 a 2003 (Figura 2), mas, como a régua do posto 7D-010 do DAEE foi desativada, em razão de um evento pluvial extremo, não se puderam medir as vazões do rio posteriores aos trabalhos nas propriedades agrícolas da BH do Rio do Peixe.

Outra forma de avaliar se as práticas conservacionistas estão adequadas, é por meio da melhoria da produção e qualidade de águas na BH. Essa comparação foi realizada por meio de imagens aéreas (antes e após a intervenção das práticas conservacionistas), tendo-se estabelecido uma correlação da melhoria da cobertura vegetal com a produção de sedimentos nas áreas agrícolas, os quais são conduzidos ao curso d'água pelas enxurradas, avaliados por meio de turbidímetro.

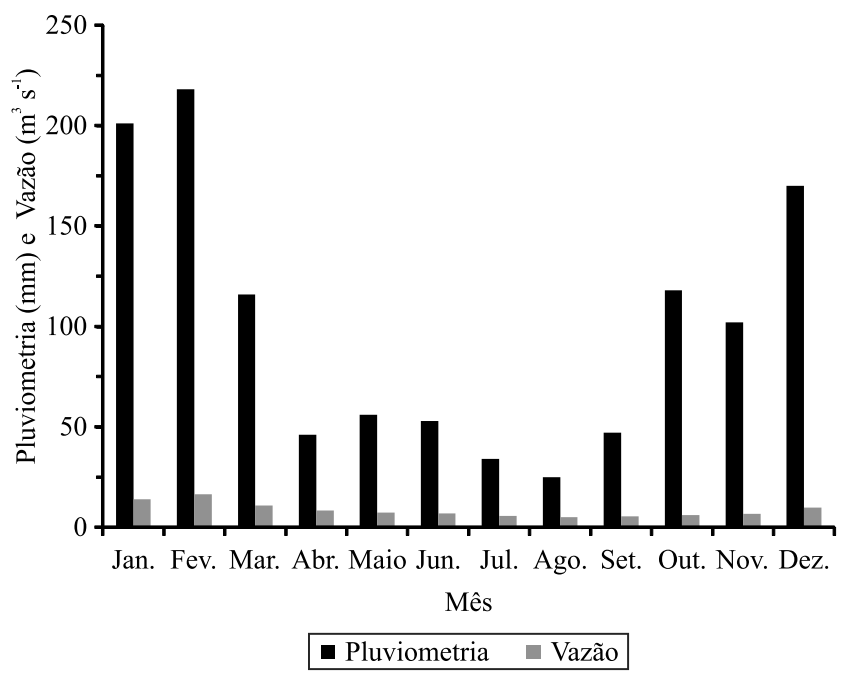

Figura 2. Pluviometria da região e vazão média mensal do Rio do Peixe, em Vera Cruz, SP. Pluviometria, média mensal histórica de 32 anos - de 1972 a 2004. Fonte: São Paulo (2014b). Vazão média mensal do Rio do Peixe no posto prefixo DAEE 7D-010, para o período de 1967 a 2003. Fonte: São Paulo (2014a).
Pela impossibilidade de se medirem as vazões do rio, no momento posterior ao desenvolvimento dos trabalhos, a avaliação foi realizada pela comparação das imagens do Google Earth com as imagens de 2002 para representar o estado da arte da $\mathrm{BH}$, consideradas como imagens anteriores, e as imagens de 2010, 2011, 2012 e 2014, para representar o que foi considerado como imagens após o desenvolvimento dos trabalhos.

Comparou-se o estado da arte, comimagens anteriores à avaliação, com imagens posteriores, do Google Earth, por meio da ferramenta imagens históricas, de 2002 e de 2012, 2013 e 2014, para avaliar o pós reabilitação agroambiental das propriedades. Para a avaliação dos indicadores de qualidade da água - turbidez, sólidos em suspensão, fósforo total e carbono orgânico dissolvido - separaram-se os dados coletados em dois períodos, considerados como os seguintes tratamentos: $\mathrm{T} 1$, dados referentes ao período denominado como "antes" da realização do trabalho, com as informações de 2000 a 2007; e T2, dados referentes ao período denominado como "depois" da realização do trabalho, considerando-se as informações de 2008 a 2014. A melhoria da qualidade da água foi avaliada por meio da determinação dos indicadores que foram tabulados e comparados por meio de gráficos elaborados para cada indicador, para os tratamentos T1 e T2. A turbidez evidencia o aporte de sedimentos no corpo d'água, em consequência da erosão do solo, e o transporte dessas partículas para o curso d'água. Definiram-se os meses em que há maior probabilidade de ocorrência de erosão e, pela maior média pluvial, determinaram-se os meses de fevereiro, outubro e dezembro, que eram também os meses de amostragem e análise da água (Figura 2). Para subsidiar as avaliações de turbidez e sólidos em suspensão nas águas, utilizaram-se para comparação as informações de Setzer (1985). Essas médias são obtidas nos postos localizados à jusante dos locais onde a bacia apresenta as maiores áreas cultivadas e localizadas à montante do curso d'água.

$O$ trabalho de fiscalização e reabilitação agroambiental da $\mathrm{BH}$ do Rio do Peixe teve início em 15 de junho de 2007 e término em fevereiro de 2011, com inspeções realizadas em todas as 176 propriedades componentes desse trecho da $\mathrm{BH}$, onde foram diagnosticadas 82 propriedades com algum tipo de erosão e outros processos degradadores do solo, que foram classificados conforme a legislação vigente no Estado de São Paulo (São Paulo, 1988). As 
propriedades restantes estavam em conformidade com a legislação de uso e conservação do solo. Foram 44 meses de trabalho das equipes de avaliação, com média de quatro propriedades por mês, ao custo estimado de $\mathrm{R} \$ 211.200,00$, referente a 176 propriedades, e custo unitário de R\$1.200,00, por propriedade.

As estradas municipais - potenciais produtoras de sedimentos, quando construídas de maneira inadequada - também foram vistoriadas, e doze trechos delas, que provocavam processos erosivos em áreas agrícolas, foram avaliadas, e alguns trechos foram readequados, para reduzir ao mínimo o assoreamento e para ficarem trafegáveis.

\section{Resultados e Discussão}

Os resultados do diagnóstico para o trecho estudado da bacia hidrográfica do Rio do Peixe apresentaram um universo de 176 propriedades, das quais, 82 tinham algum tipo de processo erosivo (Figura 3), e as demais 94 propriedades estavam em conformidade com a legislação conservacionista. Os resultados do levantamento in loco para uso e ocupação do solo (Tabela 1) mostram que predominam, na $\mathrm{BH}$, as seguintes culturas: pastagens com 9.551 ha, café com 2.232 ha, eucalipto com 41 ha, hortaliças com 14 ha, maracujá com 13 ha, culturas de ciclo anual (milho e feijão) com 12 ha, frutíferas (manga, coco e citrus) com 7 ha e, quanto à condição ambiental, mata natural que cobrem as encostas da formação conhecida como Itambé, com 1267 ha. A mata natural está presente em uma área correspondente a apenas $9 \%$ da área da $\mathrm{BH}$ do

Tabela 1. Uso e ocupação do solo na Bacia Hidrográfica Rio do Peixe, trecho de Vera Cruz, SP.

\begin{tabular}{lrc}
\hline Uso e ocupação do solo & Área (ha) & Percentagem de ocupação (\%) \\
\hline Área da Bacia Hidrográfica & 14.076 & 100,00 \\
Café & 2.232 & 15,86 \\
Pastagem & 9.551 & 67,86 \\
Hortaliças & 14 & 0,10 \\
Culturas anuais & 12 & 0,08 \\
Maracujá & 13 & 0,09 \\
Eucalipto & 41 & 0,29 \\
Cana-de-açúcar & 1 & 0,01 \\
Frutíferas & 7 & 0,05 \\
Mata natural & 1.267 & 9,00 \\
APP & 637 & 4,52 \\
Outros & 301 & 2,14 \\
\hline
\end{tabular}

Dados do diagnóstico: APP, Área de Preservação Permanente. Culturas Anuais: milho e feijão. Frutíferas: manga, coco e citros.
Rio do Peixe no trecho estudado. Santos et al. (2014) avaliaram uma BH com 11 mil ha, em Botucatu, SP, em condições de relevo semelhantes à $\mathrm{BH}$ do Rio do Peixe quanto ao uso e ocupação do solo, e encontraram 1.109 ha de mata natural, que correspondem a 9,95\% da área da bacia, situação muito semelhante à encontrada no presente trabalho.

$\mathrm{O}$ solo da $\mathrm{BH}$ foi avaliado in loco, onde se verificaram 150 pontos de controle, e o mapa de solos foi desenvolvido por meio do programa de geoprocessamento Quantum Gis. Predominam na BH o Argissolo Vermelho-Amarelo abrupto, com horizonte A moderado e textura média, e o Argissolo Vermelho-Amarelo, com horizonte A moderado e textura média. Os Neossolos Litólicos eutróficos, com textura média/argilosa, localizam-se nas encostas da formação denominada Itambé (Figura 1).

As erosões e outras formas de degradação apontadas no diagnóstico foram compiladas, e os tipos de danos encontrados foram: erosão laminar ligeira (ELL), em 1.031 ha (Figura $3 \mathrm{C}$ ); erosão laminar moderada (ELM), em 228 ha; erosão laminar severa (ELS), em 6 ha; erosão laminar extremamente severa (ELES), em 5 ha; erosão em sulco superficial ocasional (ESSO), em 1 ha; erosão em sulco superficial frequente (ESSF), em 138 ha; erosão em sulco raso ocasional (ESRO), em 11 ha; erosão em sulco raso frequente (ESRF), em 109 ha; erosão em sulco profundo ocasional (ESPO), em 40 ha (Figura $3 \mathrm{M}$ ); erosão em sulco profundo frequente (ESPF), em 72 ha; erosão em sulco muito profundo ocasional (ESMPO), em 59 ha (Figuras 3 $\mathrm{A}, \mathrm{E}$ e K); erosão em sulco muito profundo frequente (ESMPF), em 92 ha; estrada, caminho, barragem, prado e escoadouro construídos de forma inadequada que facilitaram o processo erosivo (CECBPEFIFPE), em 70 ha (Figura $3 \mathrm{G}$ ). Estes tipos totalizaram 1.861 ha de danos ao solo agrícola, em propriedades do trecho de Vera Cruz na BH do Rio do Peixe.

Pelas imagens do Googel Earth, pode-se verificar que houve eficácia nas obras implantadas na área ocupada com pastagem, que sofria processos erosivos (Figura 3 A e B), e que a adequação ambiental para a contenção de tais processos foi feita corretamente pelo proprietário, com a construção de caixas de contenção. A implantação das caixas de contenção nas pastagens foi avaliada previamente, mediante um projeto técnico de conservação do solo apresentado ao serviço de Defesa Sanitária Vegetal do Estado de São Paulo. É importante observar que o fato de haver práticas 

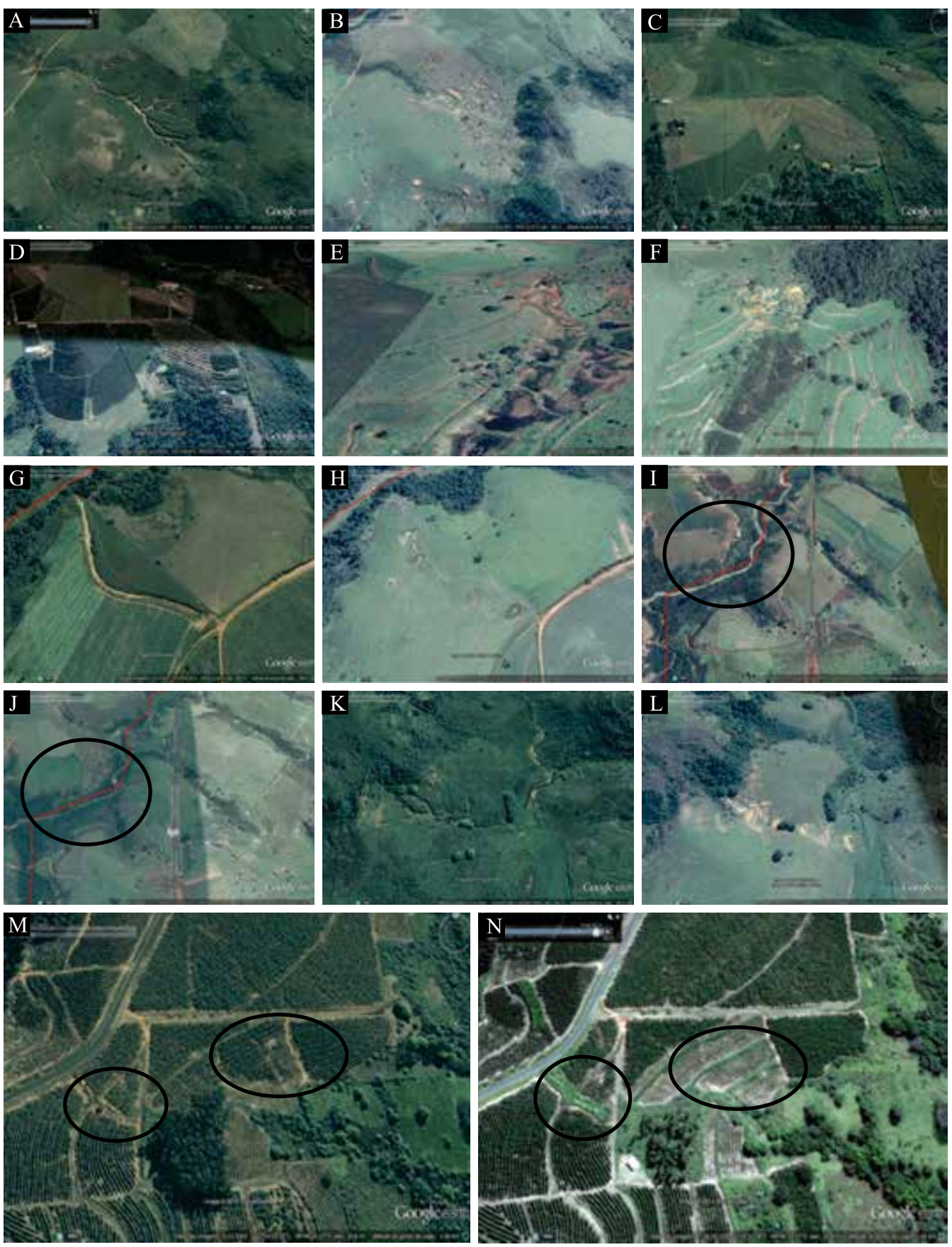

Figura 3. Imagens da área de estudo antes da implantação do projeto (A, C, E, G, I, K e M, imagens de 12/5/2002 pelo Google Earth) e depois da implantação de práticas de conservação do solo (B, D, F, H, J, L e N, imagens de16/8/2013 obtidas pelo Google Earth). A, processo erosivo, em sulco muito profundo (voçoroca); B, processo erosivo controlado com a construção de várias caixas de contenção; $\mathrm{C}$, manejo incorreto da cultura do café; $\mathrm{D}$, com a mudança do manejo do café, houve transformação da paisagem; E, manejo incorreto da pastagem; F, transformação da paisagem, com o controle das voçorocas e construção de terraços agrícolas; G, processo erosivo, em sulco muito profundo (voçoroca); H, processo erosivo totalmente controlado com a construção de caixas de contenção; I, manejo incorreto, que provocava erosões e assoreamento; $\mathrm{J}$, transformação da paisagem, pela mudança do manejo das culturas que diminui o assoreamento do rio, ver detalhe; K, processo erosivo, em sulco muito profundo (voçoroca); L, processo erosivo totalmente controlado com a construção de caixas de contenção; M, manejo incorreto da cultura do café, com vários processos erosivos (voçorocas - detalhe); e N, controle das voçorocas e transformação da paisagem, com a mudança do manejo do café (detalhe). 
voltadas à conservação da pastagem, que representa grande parte do trecho de Vera Cruz da $\mathrm{BH}$ do Rio do Peixe, além de promover benefícios importantes para a conservação do solo, pode ser mais um fator estimulador ao aumento de renda para os produtores, uma vez que, com a pastagem conservada, há maior volume de biomassa e, consequentemente, possibilidade de maior densidade animal. Fato semelhante foi observado por Zolin et al. (2011), que relatam que as maiores reduções relativas de perda de solo ocorreram nos cenários com pastagem conservada, o que indica que a otimização da conservação do solo pode ser feita com práticas de manejo conservacionista para a recuperação da pastagem.

Ainda em relação à área de pastagem, há uma ocupação no trecho estudado de 9.551 ha, que representa $67,86 \%$ da área (Tabela 1). Verifica-se também um grande predomínio do cultivo de pastagem no Estado de São Paulo, considerando-se que este cenário está em constante mudança, pois a cultura da cana-de-açúcar que, neste estudo, representa uma área de 1 ha $(0,01 \%)$, tem apresentado grande crescimento nos últimos anos com a supressão das áreas de pastagem. Os resultados encontrados são semelhantes aos de Freitas-Lima et al. (2004), que avaliaram 43.228 ha de área de pastagem do Município de Ilha Solteira, que representa 66,79\% da área total. Santos \& Hernandez (2013), por meio da determinação do uso e da ocupação do solo na microbacia na mesma região de Ilha Solteira, constataram que a área apresentou mudança do uso do solo, que apresenta $48,1 \%$ da área compreendida com a cultura da cana-deaçúcar, que era inexistente na região em anos anteriores. As últimas décadas foram caracterizadas pelas drásticas mudanças do uso e ocupação do solo na região, o que para Zalidis et al. (2002) representou uma das principais forças motrizes para a degradação ambiental, em especial sobre o solo e a água. Segundo Rodrigues et al. (2015), que analisaram a função da vegetação na interceptação da água e controle da erosão, na BH do Rio Paraíso, em São Manuel, SP, o solo descoberto apresentou aumento de $98,09 \%$ de sedimentos em comparação aos solos com cobertura vegetal.

Nas Figuras 3 E e F, por meio de método de comparação de imagens, comprova-se que o terraceamento agrícola construído na área foi eficiente no controle dos processos erosivos. Segundo Barboza (2010), a utilização das técnicas de manejo do solo, com destaque para as curvas de nível, seja em áreas de cultivo ou não, reduz a probabilidade de ocorrência de processos erosivos, pois minimiza o assoreamento dos cursos hídricos, além de preservar o solo contra prováveis degradações, em áreas de preservação permanente.

A Figura 3 A mostra uma imagem do Google Earth de 12/05/2002, no local onde havia uma erosão de grande porte (voçoroca). Após a realização dos trabalhos, o processo erosivo foi totalmente controlado com a construção de várias caixas de contenção, que contribuíram para o sucesso do projeto implantado, inclusive ao cessar os processos de assoreamento do curso d'água (Figura $3 \mathrm{~B}$ ).

A comparação entre imagens aéreas anteriores (T1) e posteriores (T2) ao estudo foi utilizada para aferir a veracidade dos resultados, método que também foi utilizado por Soares et al. (2002), que estabeleceram uma comparação visual entre os resultados obtidos por restituição estereoscópica manual. Bezerra et al. (2012) avaliaram, por meio de fotocomparação, a cobertura vegetal e o potencial de água no solo, para o acompanhamento e a recuperação de áreas degradadas em Uberlândia, $\mathrm{MG}$, e consideraram que a fotocomparação com a classificação supervisionada permitiu acompanhar o desenvolvimento da cobertura vegetal com gramíneas, bem como as suas relações com o potencial hídrico do solo.

A mudança do manejo na cultura do café proporcionou transformação positiva na paisagem (Figuras $3 \mathrm{C}, \mathrm{D}, \mathrm{M}$ e $\mathrm{N}$ ), pela qual se infere que, além de melhorar a paisagem com cobertura vegetal mais intensa (Figura $3 \mathrm{D}$ e N), houve melhoria da produtividade da cultura. $\mathrm{O}$ controle mecânico de erosões, com a construção de barragens e terraços, alteraram o local (Figuras 3 I e J), de área de degradação, para uma pastagem com capacidade produtiva (Figura $3 \mathrm{~K}$ e $\mathrm{L}$ ). Uma estrada antiga e erodida que carreava sedimentos ao leito do rio do Peixe (Figura $3 \mathrm{G}$ ) também foi corrigida com a construção de bacias de contenção (Figura $3 \mathrm{H}$ ).

O tratamento T2 apresentou dados de turbidez, sólidos em suspensão, fósforo e carbono orgânico dissolvido mais uniformes ou estáveis do que o T1 (Figuras $4 \mathrm{~A}$ a $\mathrm{H}$ ).

A turbidez da água foi menor nos meses de fevereiro e dezembro, depois da implantação do trabalho (T2), do que no período anterior à implantação do trabalho (T1) (Figuras 4 A e B). Os menores valores de turbidez são consequência da aplicação de práticas conservacionistas na área do trecho da $\mathrm{BH}$, que contribuem para a menor 
perda de solo e menor contaminação do curso d'água. Resultado semelhante foi encontrado por Souza \& Gastaldini (2014), que observaram que o uso do solo influenciou de maneira significativa os parâmetros de qualidade da água. Em áreas com maior percentual de agricultura e com problemas relacionados à erosão (situação da área antes da implantação do trabalho), os parâmetros turbidez e sólidos em suspensão são mais elevados. Esse uso do solo, sem adoção de práticas conservacionistas, pode ser considerado como o de maior potencial de erosão.

Os valores de turbidez da água, no tratamento $\mathrm{T} 1$, foram superiores ao padrão do Conselho Nacional do Meio Ambiente (1986), que é de 100 UNT (unidades nefelométricas de turbidez ) (Figura $4 \mathrm{~A}$ ), na média dos meses de fevereiro e dezembro. No tratamento T2, os valores ficaram abaixo de $100 \mathrm{UNT}$, com exceção dos meses de fevereiro, outubro e dezembro de 2009, outubro de 2012 e fevereiro de 2014 (Figura 4 B). Essa diferença no $\mathrm{T} 2$ pode ser explicada pela diminuição do aporte de sedimentos no curso d'água. Corroboraram para isso os efeitos da alteração do manejo do solo, com a adoção de práticas conservacionistas e controle das erosões por meio da implantação dos projetos de recuperação nas 82 propriedades (Figuras $3 \mathrm{~A}$ a N). Vital et al. (1999) estudaram as perdas de sedimentos em eucalipto, antes e depois do corte raso da cultura, localizada em uma $\mathrm{BH}$, e encontraram turbidez de 10, 5,5 e 7,2 UNT, nos meses de fevereiro, outubro e dezembro respectivamente, para o período anterior ao corte raso, e 8,2, 18,8 e 8,6 UNT nos meses de fevereiro, outubro e dezembro, respectivamente, para o período posterior ao corte raso. Esses valores de turbidez ficaram abaixo dos encontrados no presente estudo, e essa diferença pode ser explicada pela cobertura do solo com floresta plantada que, segundo a conclusão desses autores, são menores do que as perdas verificadas em áreas agrícolas.

Quanto aos sólidos em suspensão, os maiores valores foram registrados no tratamento T1 (Figura 4 C) do que no T2 (Figura 4 D). Em fevereiro, todos os valores foram iguais ou maiores do que $100 \mathrm{mg}$ $\mathrm{L}^{-1}$; o mesmo fato aconteceu com os valores de dezembro, com exceção do ano de 2007. No T2, os valores se mostraram mais uniformes, apenas com pico observado em outubro de 2012 (Figura 4 D), mas que ainda ficou abaixo dos picos registrados no T1 em 2006 (Figura 4 C). Os resultados de sólidos em suspensão para o período chuvoso foram inferiores aos descritos por Setzer (1985), que avaliou as perdas de solo e sua relação com a turbidez e os parâmetros das águas em diversas BHs no Estado de São Paulo, e concluiu que as médias anuais para sólidos em suspensão, nos rios paulistas, são pouco inferiores a $150 \mathrm{mg} \mathrm{L}^{-1}$, que aumentam à quase $300 \mathrm{mg} \mathrm{L}^{-1}$ nos meses mais chuvosos e diminuem a menos de $50 \mathrm{mg} \mathrm{L}^{-1}$ nos meses mais secos. Conforme Vital et al. (1999), os valores de sólidos em suspensão, antes do corte raso do eucalipto de 20,6, 13,8 e 13,9 $\mathrm{mg} \mathrm{L}^{-1}$ para os meses de fevereiro, outubro e dezembro, respectivamente, e 33,6 e $24,2 \mathrm{mg} \mathrm{L}^{-1}$ para os meses de fevereiro e dezembro, respectivamente, foram inferiores aos valores do presente estudo, explicados pelo tipo de cobertura vegetal; os resultados desse estudo evidenciam que houve diminuição significativa dos sólidos em suspensão, após a adoção de práticas conservacionistas e a reabilitação das propriedades agrícolas. Em estudo de Rodrigues et al. (2015), o coeficiente de escoamento superficial foi baixo na presença da vegetação, o que resultou em maior infiltração e melhor regularidade da vazão; esses autores avaliaram também que a erosão e os sedimentos carreados aumentaram nos solos desprotegidos e alteraram a dinâmica da água no solo.

$\mathrm{O}$ fósforo total dissolvido em água apresentou valores superiores ao padrão que é de $0,025 \mathrm{mg} \mathrm{L}^{-1}$, conforme Resolução Conama 20/86 (Conama, 1986), e maiores no T1 (Figura 4 E) do que no T2 (Figura 4 $\mathrm{F})$. Os valores de fósforo para $\mathrm{T} 2$ ficaram próximos a $0,10 \mathrm{mg} \mathrm{L}^{-1}$, com exceção dos picos registrados em dezembro - de 2008, 2009 e 2010 -, e em outubro de 2009 e 2012, cujos picos atingiram mais de 0,30 $\mathrm{mg} \mathrm{\textrm {L } ^ { - 1 }}$, mesmo assim esses valores ficaram abaixo dos picos do T1, em 2001, 2002, 2003 e 2005, que atingiu 0,50 $\mathrm{mg} \mathrm{L}^{1}$, em dezembro de 2005 (Figura 4 E). Os resultados mostram valores acima dos obtidos por Donadio et al. (2005), que avaliaram a qualidade da água em uma BH em Taquaritinga, SP, cujo solo predominante é o Argissolo, e os valores médios de fósforo na água foram de $1,58 \mathrm{mg} \mathrm{L}^{-1}$, para o período seco do ano, e de 4,32 $\mathrm{mg} \mathrm{L}^{1}$, para o período chuvoso. Os valores inferiores de fósforo encontrados por esses pesquisadores podem ser explicados pela presença de remanescentes de vegetação ciliar, que auxiliam a proteção dos recursos hídricos, minimizando o aporte de sedimentos com nutrientes no corpo d'água, fato pouco observado na BH do Rio do Peixe, trecho de Vera Cruz. Os resultados de fósforo encontrados por Pinheiro et al. (2014), que estudaram o uso e ocupação 

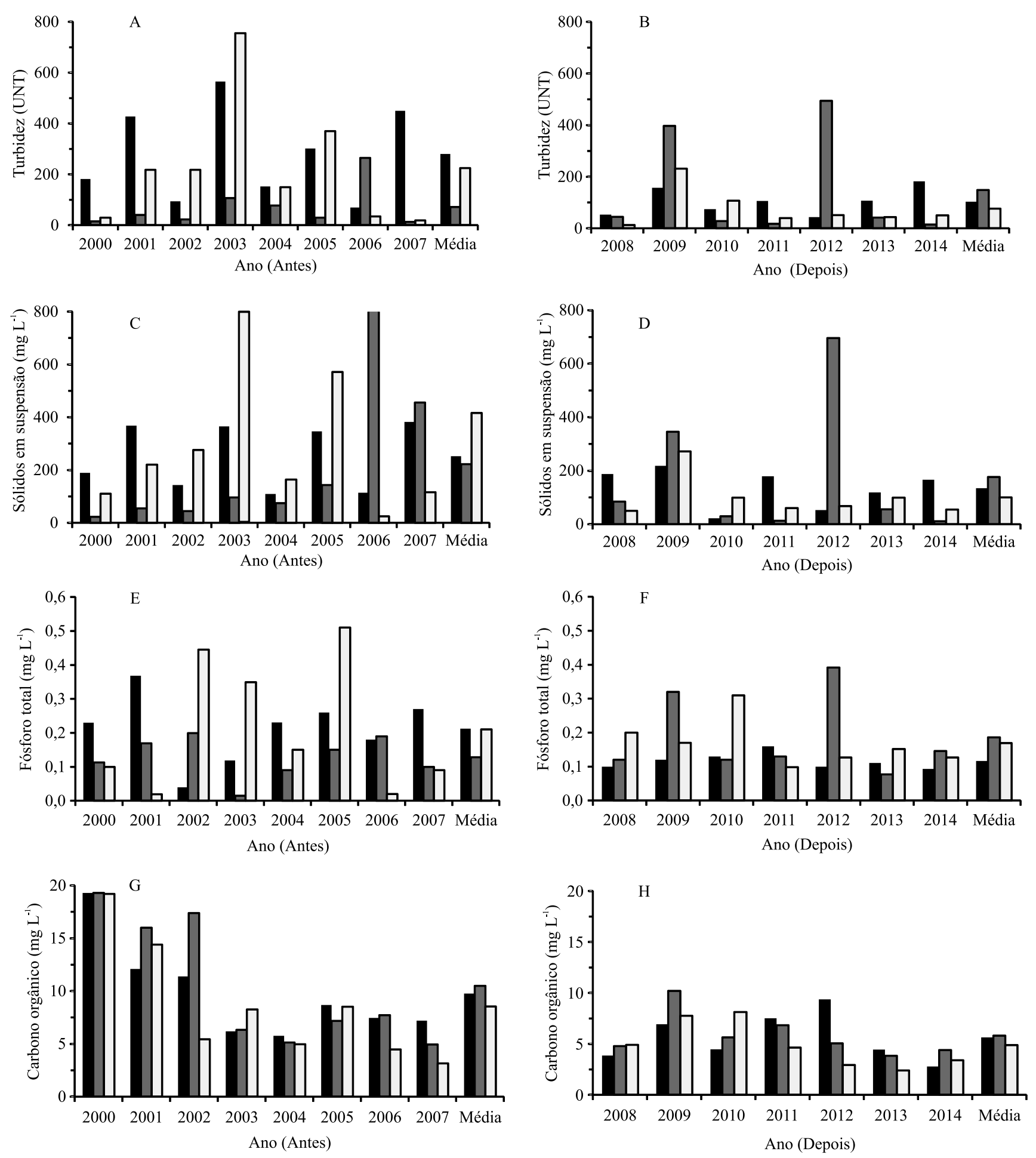

\begin{tabular}{|ll|}
\hline - Fevereiro $\quad$ DOutubro & aDezembro \\
\hline
\end{tabular}

Figura 4. Turbidez (A, B padrão Conama $100 \mathrm{UNT}$ ), sólidos em suspensão $(\mathrm{C}, \mathrm{D})$, fósforo total (E, F, padrão Cetesb $\left.0,025 \mathrm{mg} \mathrm{L}^{-1}\right)$ e carbono dissolvido $(\mathrm{G}, \mathrm{H})$ na água coletada no posto PEIX02100, no Rio do Peixe, considerando-se como anteriores ao projeto os anos 2000 a 2007 (T1), e posteriores à implantação do projeto os anos 2008 a 2014 (T2). Fontes: Conama (1986) e Cetesb (2015). 
do solo e a relação com a qualidade da água em duas subáreas da BH do Rio Duas Mamas em Santa Catarina, foram de 27, 3 e 41,6 $\mathrm{mg} \mathrm{L}^{-1}$ superiores, portanto, aos resultados do presente estudo. Esse resultado deveu-se, provavelmente, ao fato de que, em uma das subáreas avaliadas pelos autores, há cultivo de bananeira e de outras culturas anuais, apesar da grande percentagem de mata natural remanescente.

Os dados de carbono orgânico dissolvido na água foram superiores no $\mathrm{T} 1 \mathrm{em}$ todos os períodos (fevereiro, outubro e dezembro) e atingiram valores de carbono acima de $18 \mathrm{mg} \mathrm{L}^{-1}$ no ano 2000. No tratamento $\mathrm{T} 2$, a média dos valores de carbono ficaram entre 4 e $6 \mathrm{mg} \mathrm{L}^{-1}$, enquanto no $\mathrm{T} 1$ ficaram entre $8 \mathrm{e}$ $10 \mathrm{mg} \mathrm{L}^{-1}$ (Figura $4 \mathrm{G}$ ). Verifica-se que a quantidade de carbono na água, após a implantação do projeto, foi inferior a situação anterior à implantação; neste caso, as práticas conservacionistas implantadas contribuíram para uma menor quantidade de sedimentos erodidos. Este resultado corrobora a afirmação de Silva et al. (2005), em que o carbono orgânico foi o constituinte encontrado em maior quantidade de sedimentos erodidos. Assim, é importante enfatizar a necessidade de práticas conservacionistas que reduzam a ação erosiva da chuva, para manter esta fração orgânica no solo, uma vez que ela é importante para a manutenção da estrutura, retenção de umidade e CTC, entre outros atributos do solo.

Os valores menores dos indicadores encontrados no tratamento T2 (Figura $4 \mathrm{H}$ ) evidenciam que o trabalho conservacionista de reabilitação das propriedades agrícolas obteve sucesso e contribuiu para a melhoria da cobertura vegetal e da qualidade da água na $\mathrm{BH}$ do Rio do Peixe.

\section{Conclusões}

1. As práticas de manejo conservacionista do solo e da água implantadas em 86 propriedades da bacia permitem alteração positiva da paisagem e de rendimento da atividade agrícola, mudança comprovada pelas imagens aéreas e pelos indicadores de qualidade da água.

2. A metodologia apresentada de monitoramento e de reabilitação agroambiental é viável e pode contribuir para o manejo e o monitoramento de microbacias.

\section{Agradecimentos}

AOscar Norio Yasuda, diretor do Escritório de Defesa Agropecuária (EDA) de Marília em 2007, e a Edna Aparecida Menegucci Scachetti, atual diretora do EDA de Marília, pelo empenho e apoio ao desenvolvimento deste trabalho; aos Engenheiros Agrônomos da Secretaria de Agricultura e Abastecimento do Estado de São Paulo, Coordenadoria de Defesa Agropecuária que participaram das avaliações: Marco Parminondi, in memorian, e Nelson Baggio, in memorian, Edilson Cavalini, Marcelo Braghetta Camargo, Antonio Celso Vilella, Clésio Alves Ferreira, João Casadei de Baptista, Miguel Motta e Antonio Paulo Ronchi.

\section{Referências}

ANA. AGÊNCIA NACIONAL DE ÁGUAS (Brasil). Programa Produtor de Água: manual operativo. Brasília, 2009. 67p.

BARBOZA, G.C. Monitoramento da qualidade e disponibilidade da água do Córrego do Coqueiro no Noroeste Paulista para fins de irrigação. 2010. 143p. Dissertação (Mestrado) - Universidade Estadual Paulista Júlio de Mesquita Filho, Ilha Solteira.

BEZERRA, J.F.R.; GUERRA, A.J.T.; RODRIGUES, S.C. Relações entre potencial matricial no solo e cobertura vegetal em uma estação experimental, Uberlândia - MG. Sociedade \& Natureza, ano 24, p.103-114, 2012.

BEZERRA, M.A.; ETCHEBEHERE, M.L. de C.; SAAD, A.R.; CASADO, F. da C. Análise geoambiental da região de Marília, SP: suscetibilidade a processos erosivos frente ao histórico de ocupação da área. Geociências, v.28, p.425-440, 2009.

BRASIL. Decreto $n^{\circ}$ 94.076, de 5 de março de 1987. Institui o Programa Nacional de Microbacias Hidrográficas, e dá outras providências. Diário Oficial [da] República Federativa do Brasil, Brasília, 6 mar. 1987. Seção 1, p.3159.

CETESB. COMPANHIA AMBIENTAL DO ESTADO DE SÃO PAULO. Publicações e relatórios. [Resultados dos parâmetros e indicadores de qualidade das águas: posto de coleta prefixo 00SP21438PEIX02100: relatórios dos anos 2007 a 2014]. Disponível em: <http://aguasinteriores.cetesb.sp.gov.br/ publicacoes-e-relatorios/>. Acesso em: 16 maio 2015.

CONAMA. CONSELHO NACIONAL DO MEIO AMBIENTE (Brasil). Resolução nº 20, de 18 de junho de 1986. [Estabelece a classificação das águas doces, salobras e salinas, segundo seus usos preponderantes, em nove classes]. Diário Oficial [da] República Federativa do Brasil, Brasília, 30 jul. 1986. Seção 1.

DONADIO, N.M.M.; GALBIATTI, J.A.; PAULA, R.C. Qualidade da água de nascentes com diferentes usos do solo na Bacia Hidrográfica do Córrego Rico, São Paulo, Brasil. Engenharia Agrícola, v.25, p.115-125, 2005. DOI: 10.1590/S010069162005000100013 . 
FREITAS-LIMA, E.A.C.; SILVA, H.R.; ALTIMARE, A.L. Uso atual da terra no Município de Ilha Solteira, SP, Brasil: riscos ambientais associados. Holos Environment, v.4, p.81-96, 2004.

GALHARTE, C.A.; CRESTANA, S. Avaliação do impacto ambiental da integração lavoura-pecuária: aspecto conservação ambiental no Cerrado. Revista Brasileira de Engenharia Agrícola e Ambiental, v.14, p.1202-1209, 2010. DOI: 10.1590/ S1415-43662010001100010.

MINELLA, J.P.G.; MERTEN, G.H.; REICHERT, J.M.; SANTOS, D.R. Identificação e implicações para a conservação do solo das fontes de sedimentos em bacias hidrográficas. Revista Brasileira de Ciência do Solo, v.31, p.1637-1646, 2007. DOI: 10.1590/ S0100-06832007000600039.

PINHEIRO, A.; SCHOEN, C.; SCHULTZ, J.; HEINZ, K.G.H.; PINHEIRO, I.G.; DESCHAMPS, F.C. Relação entre o uso do solo e a qualidade da água em bacia hidrográfica rural no bioma Mata Atlântica. Revista Brasileira de Recursos Hídricos, v.19, p.127139, 2014.

RODRIGUES, V.A.; SÁNCHEZ-ROMÁN, R.M.; TARJUELO, J.M.; SARTORI, M.M.P.; CANALES, A.R. Avaliação do escoamento e interceptação da água das chuvas. Irriga, v.1, p.113, 2015. Edição especial, 20 anos Irriga +50 anos FCA. DOI: 10.15809/irriga.2015v1n1p01.

SANTOS, G.O.;HERNANDEZ,F.B.T.Uso do soloemonitoramento dos recursos hídricos no Córrego do Ipê, Ilha Solteira, SP. Revista Brasileira de Engenharia Agrícola e Ambiental, v.17, p.60-68, 2013. DOI: $10.1590 /$ S1415-43662013000100009.

SANTOS, G.O.; HERNANDEZ, F.B.T.; FRANCO, R.A.M.; FEITOSA, D.G.; BARBOSA, G.C.; LIMA, R.C. Influência do uso e ocupação do solo na qualidade de água para fins de irrigação no Córrego do Ipê, noroeste do Estado de São Paulo. In: Simpósio Brasileiro de Sensoriamento Remoto, 15., 2011, Curitiba. Anais. São José dos Campos: Inpe, 2011. p.1263-1270. Editores: José Carlos Neves Epiphanio e Lênio Soares Galvão.

SANTOS, J.B.; PEZZONI FILHO, J.C.; DANTAS, M.J.F.; ZIMBACK, C.R.L.; LESSA, L.G.F. Avaliação da adequação da ocupação do solo em Áreas de Preservação Permanente (APPs). Irriga, v.19, p.333-344, 2014. DOI: 10.15809/ irriga.2014v19n2p333.

SANTOS, V.G.; DIAS, H.C.T.; SILVA, A.P. de S.; MACEDO, M. de N.C. de. Análise hidrológica e socioambiental da Bacia Hidrográfica do Córrego Romão dos Reis, Viçosa, MG. Revista Árvore, v.31, p.931-940, 2007. DOI: 10.1590/S0100-67622007000500017.

SÃO PAULO (Estado). Coordenadoria de Defesa Agropecuária. [Metodologia de fiscalização em bacias hidrográficas]. In: Programa Conservação do Solo. Disponível em: <http:// www.defesa.agricultura.sp.gov.br/www/programas/index. php? action $=$ view $\& \operatorname{cod}=28 \&$ ar $=3 \& n m=$ Conserva $\% E 7 \% E 30 \% 20$
e\%20preserva\%E7\%E3o\%20do\%20solo>. Acesso em: 16 maio 2015.

SÃO PAULO (Estado). Departamento de Águas e Energia Elétrica. Hidrologia. Banco de dados hidrológicos: fluviométricos: UGRHI: Peixe: 7D-010. Disponível em: <http://www.hidrologia. daee.sp.gov.br>. Acesso em: 25 jul. 2014a.

SÃO PAULO (Estado). Departamento de Águas e Energia Elétrica. Hidrologia. Banco de dados hidrológicos: pluviométricos: Marília: D6-098. Disponível em: <http://www.hidrologia.daee. sp.gov.br/>. Acesso em: 25 jul. $2014 b$.

SÃO PAULO (Estado). Lei n 6.171, de 04 de julho de 1988. Dispõe sobre o uso, conservação e preservação do solo agrícola. Diário Oficial [do] Estado de São Paulo, São Paulo, 5 jul. 1988.

SETZER, J. Transporte sólido por suspensão em rios paulistas. São Paulo: CTH/DAEE/EPUSP, 1985. 106 p.

SILVA, A.M. da; SILVA, M.L.N.; CURI, N.; LIMA, J.M. de; AVANZI, J.C.; FERREIRA, M.M. Perdas de solo, água, nutrientes e carbono orgânico em Cambissolo e Latossolo sob chuva natural. Pesquisa Agropecuária Brasileira, v.40, p.1223-1230, 2005. DOI: 10.1590/S0100-204X2005001200010.

SOARES, V.P.; MOREIRA, A.A.; RIBEIRO, J.C.; RIBEIRO, C.A.A.S.; SILVA, E. Avaliação das áreas de uso indevido da terra em uma microbacia no Município de Viçosa - MG, através de fotografias aéreas e sistemas de informação geográfica. Revista Árvore, v.26, p.243-251, 2002.

SOUZA, M.M. de; GASTALDINI, M. do C.C. Avaliação da qualidade da água em bacias hidrográficas com diferentes impactos antrópicos. Engenharia Sanitária e Ambiental, v.19, p.263-274, 2014. DOI: 10.1590/S1413-41522014019000001097.

VITAL, A.R.T.; LIMA, V. de P.; CAMARGO, F.R.A. de. Efeitos do corte raso de plantação de Eucalyptus sobre o balanço hídrico, a qualidade da água e as perdas de solo e de nutrientes em uma microbacia no Vale do Paraíba, SP. Scientia Forestalis, n.55, p.5-16, 1999.

ZALIDIS, G.; STAMATIADIS, S.; TAKAVAKOGLOU, V.; ESKRIDGE, K.; MISOPOLINOS, N. Impacts of agricultural practices on soil and water quality in the Mediterranean region and proposed assessment methodology. Agriculture, Ecosystems and Environment, v.88, p.137-146, 2002. DOI: 10.1016/S01678809(01)00249-3.

ZOLIN, C.A.; FOLEGATTI, M.V.; MINGOTI, R.; SÁNCHEZROMÁN, R. M.; PAULINO, J.; GONZÁlES, A.M.G.O. Minimização da erosão em função do tamanho e localização das áreas de floresta no contexto do programa "Conservador das Águas". Revista Brasileira Ciências do Solo, v.35, p.2157-2166, 2011. DOI: 10.1590/S0100-06832011000600030.

$\overline{\text { Recebido em } 16 \text { de julho de } 2015 \text { e aprovado em } 5 \text { de fevereiro de } 2016}$

Pesq. agropec. bras., Brasília, v.51, n.9, p.1099-1109, set. 2016 DOI: $10.1590 / \mathrm{S} 0100-204 X 2016000900009$ 